\title{
Transgender men's preferences when choosing obstetricians and gynecologists
}

\author{
Dror Lifshitz 1,5*0 \\ Foad Azem ${ }^{4}$ and Hadar Amir ${ }^{4}$
}

\begin{abstract}
Background: Transgender men are a marginalized population with unique health care needs. However, their usage of health services is low because of considerable discrimination. A major factor in their avoidance is patient-provider interactions.

Methods: This cross-sectional study included 102 transgender men who anonymously completed a 55-item questionnaire in clinic, between 10/2017 and 01/2019. In addition, 92 transgender women filled out the part about family physician's preferences. We examined which characteristics transgender men prefer in their obstetricians/gynecologists in order to promote their usage of healthcare services.

Results: A small majority of the transgender men (54.1\%) had no gender preference for their obstetrician/gynecologist, while $42.9 \%$ preferred a female obstetrician/gynecologist and 3.1\% preferred a male obstetrician/gynecologist. Most transgender men with a same-gender preference preferred female obstetricians/gynecologists for both invasive procedures (e.g., pelvic examination, 97.4\%) and non-invasive procedures (e.g., cesarean section, 60\%). The reasons for preferences regarding invasive procedures were feeling comfortable, embarrassment and feeling that female obstetricians/gynecologists are gentler. Transgender men who preferred female obstetricians/gynecologists ranked ability (90.5\%), sexual tolerance (92.9\%) and gender identity tolerance (90.5\%) as the top three desirable qualities of obstetricians/gynecologists, while the responders who did not prefer female ranked ability (94.6\%), experience (92.9\%) and knowledge (92.9\%) as the top three qualities. Transgender men with female preferences considered female obstetricians/gynecologists to be more accepting of gender identity compared to the responders that did not prefer females (47.5\% vs. $9.1 \%, P<.001)$.
\end{abstract}

Conclusion: A small majority of the transgender men exhibited no gender preference when choosing an obstetrician/gynecologist, although 42.9\% preferred females. The latter choice was associated with the assumption that female obstetricians/gynecologists are more tolerant towards their transgender men patients. Educating the medical staff about their special needs and establishing dedicated SGM centers staffed with high percentages of female healthcare providers are highly recommended.

Keywords: Transgender men, Obstetricians/gynecologists, Gender, Tolerant, Sexual and gender minorities

*Correspondence: dror_lifshitz@hotmail.com

${ }^{5}$ Department of Obstetrics and Gynecology, Chaim Sheba Medical Center (Tel Hashomer), Ramat Gan, Israel

Full list of author information is available at the end of the article

\section{Background}

Transgender individuals are defined as those with a discrepancy between their sex assigned at birth and their personal gender identity (cis-centric) [1], a situation which often leads to severe mental distress (gender dysphoria). They are estimated to comprise around $0.5-0.6 \%$ of the population in the U.S. [2] with youth 
population approximately $2 \%$ [3], and reportedly range as high as $1.2 \%$ in other countries worldwide [4]. Transgender people have unique health issues compared to individuals whose gender identity matches the sex they were assigned at birth (cisgender) [1, 4], including a higher prevalence of risky health behaviors (smoking, alcohol and drug use) [5], mental health problems (depression, anxiety, and suicidality), and HIV and other sexually transmitted infections [6]. The poor health outcomes in this marginalized population have been explained by structural (e.g., laws and policies), interpersonal (e.g., provider discrimination) and individual (e.g., provider education and knowledge) barriers to healthcare [7]. Public awareness about transgender people has recently grown considerably, and the field of transgender health is experiencing a corresponding surge in interest on the part of policymakers and health providers. The World Health Organization has identified transgender people as comprising a population with high vulnerability and specific health needs that need to be addressed [8]. In 2016, the Obama administration expanded Sect. 1577, which prohibits discrimination by any federal health program on activity on the grounds of race, color, national origin, sex, age, or disability, to include prohibition of discrimination based on gender [9].

Providing transgender individuals adequate medical care is even more complex when it comes to procedures that are perceived by transgender patients as being invasive and cause them discomfort and distress [10]. Transgender men (individuals who were labelled as being females at birth but have a male gender identity) whose reproductive organs have not been removed require gynecological surveillance, including screening examinations, in order to prevent life-threatening medical conditions. Additionally, transgender men who choose to conceive, be pregnant and give birth are subject to the routine gynecological examinations. The American College of Obstetricians and Gynecologists called on obstetricians/gynecologists to help eliminate barriers for transgender men by creating nondiscriminatory practices, assisting with gender transition, and providing transgender-appropriate and comprehensive healthcare [11]. However, the obstetricians/gynecologic needs of transgender men are not taken care of and they use less the obstetric/gynecologic services, such as fertility preservation [10-12].

A key approach in today's healthcare is patient-centered care which acknowledges the patient's needs and preferences. This is especially important for populations with unique health needs and for areas of medicine that require a pelvic examination. The factors that affect the patient's choice of an obstetrician/gynecologist have recently been under investigation. Several papers that examined the influence of the physician's gender in those choices among non-sexual and gender minorities (SGM) reported conflicting findings: some reported a clear preference for female physicians in the cisgender population [13], while others stated that the gender of their physician was not an important consideration when choosing an obstetrician/gynecologist [14]. Moreover, the choice of a female obstetrician/gynecologist was consistently more common among religious and ethnic minorities, primarily due to a sense of embarrassment during a pelvic examination [15]. Similarly, lesbians were found to prefer a female obstetrician/gynecologist because they felt more comfortable and described them as being gentler, kind, understanding, open and tolerant compared to male obstetricians/gynecologists [16, 17].

It is incumbent among medical providers to enable and encourage transgender men to obtain the medical care that they require. The aim of the current study was to explore transgender men' preferences, including gender, when choosing their obstetricians/gynecologists, and to identify the factors that need to be modified in the healthcare system in order to promote greater accessibility and use of appropriate medical care of these individuals.

\section{Methods}

\section{Ethical approval}

This study was approved by the institutional review board of the Tel Aviv Sourasky Medical Center (TASMC) (\#0455-17-TLV).

\section{Study population and participant recruitment}

In light of the anticipated difficulty in recruiting transgender people [18], we chose to perform the study in two clinics that provide services mainly to SGM patients. All the consecutive eligible patients aged 18 years and above were asked to fill out the anonymous questionnaire before entering a meeting with the physician. After collecting a total of 200 questionnaires, a similar number of questionnaires were analyzed in previous studies that we conducted among minority populations, the recruitment process was stopped.

Of 113 transgender men and 101 transgender women (individuals who were labelled male at birth but have a female gender identity) 102 transgender men (90\% response rate) and 92 transgender women (91\% response rate) were prospectively enrolled and included in our analyses. Four transgender men completed solely the first part of the questionnaire and therefore were included in this part of the survey only. The participants were referred to the Gender Clinic, Institute of Endocrinology, Metabolism and Hypertension of TASMC, a tertiary university-affiliated medical center, and to the Gender 
Clinic, Gan Meir Community Health Care Center, Clalit Health Services, Tel Aviv, Israel between October 2017 and January 2019.

The patients met with endocrinologists in the first clinic visit and with a family physician in the second visit. Patients who were referred to both clinics were asked to fill out the anonymous questionnaire before entering a meeting with the physician. Transgender men completed an anonymous questionnaire designed to assess gender preferences in choosing their healthcare providers, including obstetricians/gynecologists. Transgender women were asked to fill out the part about their family physician's preferences. All patients received an explanation of the questionnaire from the nurse, filled out the questionnaire independently in the waiting room, and then put it through a slot in a closed box. The researchers emptied the box daily and transferred the data provided in the forms to a computerized database.

\section{Questionnaire for the transgender men}

The researchers designed the study questionnaire of 55 items based on previous studies [13, 14]. The first part of the questionnaire included basic sociodemographic and clinical information, and those items were answered by circling the selected choice. The second part included questions about gender preferences of provider, gender preferences for different medical situations, such as pelvic examinations, pregnancy follow-up visits, gynecologic surgeries, in vitro fertilization treatment or any other consultation for obstetric or gynecologic issues. The transgender men were further asked to identify specific characteristics of the obstetrician/gynecologist related to their gender preference by circling the word "male", "female" or "none". Lastly, each participant was also asked to circle characteristics he considered to be the most important in choosing his obstetrician/gynecologist from a list of 16 .

\section{Statistical analysis}

Descriptive statistics were computed as mean and standard deviation (SD) for continuous variables and as frequencies for categorical variables. Significance was tested with the t-test, Mann-Whitney U test, $\chi^{2}$ and Fisher's exact test as needed. The data are summarized as mean $\pm \mathrm{SD}$, or number of responders (percentage) according to the variables. $P<0.05$ was considered statistically significant. All statistical analyses were performed with IBM SPSS Statistics version 25.

\section{Results}

The study population was comprised of 102 transgender men (mean age $27 \pm 8.16$, range 18-62 years). In addition, 92 transgender women (mean age $28 \pm 8.2$, range
18-57 years) filled out the part about family physician's preferences. No significant socio-demographic or clinical differences were found between the two groups except for upper body surgery (Table 1). A significantly higher rate of upper body surgery was performed among transgender men compared to transgender women ( $48 \%$ vs. $20.7 \%$, respectively, $P<0.001)$.

As shown in Table 2, about one-half of each group of transgender women and men were routinely managed by male family physicians $(47.3 \%$ and $42.4 \%$, respectively, $P=0.194$ ) and the other half by female family physicians (39.6\% and $50.5 \%$, respectively, $P=0.194$ ). Most of the study participants had no gender preference for their family physician $(59.6 \%$ of transgender women and $64.6 \%$ of transgender men, $P=0.242$ ).

We next explored the physician preferences of transgender men when choosing an obstetrician/ gynecologist. Fifty-three (54.1\%) had no gender preference and $42(42.9 \%)$ preferred a female obstetrician/ gynecologist, a higher figure than the $29.3 \%$ of them who preferred a female family physician. Only three (3.1\%) replied that they preferred a male obstetrician/ gynecologist (Fig. 1). The preference for a female obstetrician/gynecologist was more common among lesseducated patients compared to a male obstetrician/ gynecologist or no gender preference (Table 3). Primary school- and high school-educated students indicated a female preference $(11.9 \%$ vs. $1.8 \%$ and $64.3 \%$ vs. $55.4 \%$, respectively, $P=0.04$ ), while college/university graduates did not $(23.8 \%$ vs. $42.9 \%, P=0.04)$. Preferring a female obstetrician/gynecologist was also more common among the same transgender men who preferred a female family physician compared to a male or no gender preference of family physician $(38.3 \%$ versus $7.3 \%$, respectively; $P<0.001$ ).

Table 4 and Fig. 2 displays gender preferences for invasive versus non-invasive aspects of gynecological care. Transgender men who preferred a female obstetrician/ gynecologist chose a female obstetrician/gynecologist for both invasive and non-invasive procedures compared to transgender men who did not $(P<0.001)$. Almost all of the transgender men who preferred female obstetricians/ gynecologists preferred them for pelvic examinations (97.4\%) and most (82.5\%) preferred them for pregnancy follow-up procedures that are considered invasive. However, the preference for a female obstetrician/gynecologist was less pronounced when it came to non-invasive procedures, such as a caesarian Sect. (60\%). Interestingly, the percentage of transgender men who preferred female obstetricians/gynecologists for surgical procedures such as gynecological surgery (52.5\%) was lower than for non-surgical procedures, such as pregnancy follow-up (82.5\%). 
Table 1 Demographic and clinical characteristics of the 194 transgender responders to the study survey

\begin{tabular}{|c|c|c|c|}
\hline Characteristic & $\begin{array}{l}\text { Transgender } \\
\text { women }(n=92) \\
n,(\%)\end{array}$ & $\begin{array}{l}\text { Transgender } \\
\text { men }(n=102) \\
n,(\%)\end{array}$ & $P$ value \\
\hline $\begin{array}{l}\text { Age, mean (SD) } \\
\text { (range) }\end{array}$ & $28(8.2)(18-57)$ & $27(8.16)(18-62)$ & NS \\
\hline \multicolumn{4}{|l|}{ Origin } \\
\hline Israel & $69(82.1)$ & $85(84.2)$ & \\
\hline Other & $15(17.9)$ & $16(15.8)$ & NS \\
\hline \multicolumn{4}{|l|}{ Religion } \\
\hline Jewish & 76 (82.6) & 89 (87.3) & \\
\hline Other & $16(17.4)$ & $13(12.7)$ & NS \\
\hline \multicolumn{4}{|l|}{ Religious status } \\
\hline Secular & $72(79.1)$ & $81(82.7)$ & \\
\hline Religious & 19 (20.9) & $17(17.3)$ & NS \\
\hline \multicolumn{4}{|l|}{ Marital status } \\
\hline $\begin{array}{l}\text { Married or with a } \\
\text { partner }\end{array}$ & $19(20.7)$ & $35(35.4)$ & \\
\hline Single or divorced & $73(79.3)$ & $64(64.6)$ & NS \\
\hline \multicolumn{4}{|l|}{ Children } \\
\hline Yes & $7(7.6)$ & $8(8.1)$ & \\
\hline No & 85 (92.4) & 91 (91.9) & NS \\
\hline \multicolumn{4}{|l|}{ Education } \\
\hline Primary school & $10(11.5)$ & $6(5.9)$ & \\
\hline High school & $50(57.5)$ & $61(59.8)$ & \\
\hline $\begin{array}{l}\text { College degree or } \\
\text { higher }\end{array}$ & $27(31)$ & $35(34.3)$ & NS \\
\hline \multicolumn{4}{|l|}{ Employment } \\
\hline Yes & $61(66.3)$ & $64(64.6)$ & \\
\hline No & $31(33.7)$ & $35(35.4)$ & NS \\
\hline \multicolumn{4}{|l|}{ Sexual orientation } \\
\hline Heterosexual & $54(60.7)$ & $43(43.9)$ & \\
\hline Homosexual & $20(22.5)$ & $15(15.3)$ & \\
\hline Bisexual & $12(13.5)$ & $33(33.7)$ & \\
\hline Asexual & $3(3.4)$ & $7(7.1)$ & NS \\
\hline \multicolumn{4}{|l|}{ Psychiatric medication } \\
\hline Yes & $32(35.6)$ & $28(28)$ & \\
\hline No & $58(64.4)$ & $72(72)$ & NS \\
\hline \multicolumn{4}{|c|}{ Gender-affirming hormone therapy } \\
\hline None & $15(17.6)$ & $22(22.9)$ & \\
\hline Less than one year & $26(30.6)$ & $25(26)$ & \\
\hline $1-5$ years & $39(45.9)$ & $39(40.6)$ & \\
\hline More than 5 years & $5(5.9)$ & $10(10.4)$ & NS \\
\hline \multicolumn{4}{|l|}{ Upper body surgery } \\
\hline Yes & $19(20.7)$ & $49(48)$ & \\
\hline No & $73(79.3)$ & $53(52)$ & $<0.001$ \\
\hline \multicolumn{4}{|l|}{ Lower body surgery } \\
\hline Yes & $7(7.8)$ & $4(4)$ & \\
\hline No & $83(92.2)$ & $96(96)$ & NS \\
\hline
\end{tabular}

Bold represents $P$-value under 0.05 was considered to be significant
Table 2 Gender preference for family physician of 194 transgender responders to the study survey

\begin{tabular}{|c|c|c|c|}
\hline Characteristic & $\begin{array}{l}\text { Transgender } \\
\text { women }(n=92) \\
n,(\%)\end{array}$ & $\begin{array}{l}\text { Transgender men } \\
(n=102) n,(\%)\end{array}$ & $P$ Value \\
\hline \multicolumn{4}{|c|}{ Family physician's gender (last 3 years) } \\
\hline Male & $43(47.3)$ & $42(42.4)$ & \\
\hline Female & $36(39.6)$ & $50(50.5)$ & \\
\hline None & $12(13.2)$ & $7(7.1)$ & NS \\
\hline \multicolumn{4}{|c|}{ Preferred gender for family physician } \\
\hline Male & $2(2.2)$ & $6(6.1)$ & \\
\hline Female & $34(38.2)$ & $29(29.3)$ & \\
\hline None & $53(59.6)$ & $64(64.6)$ & NS \\
\hline
\end{tabular}

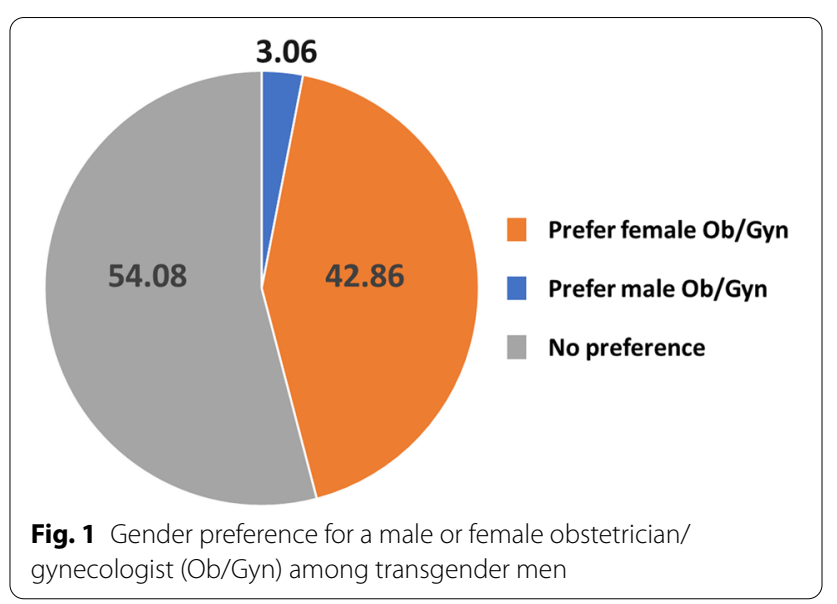

The reasons for preferring a female obstetrician/ gynecologist were then queried (Table 5). The major reason given by the transgender men who preferred a female over a male obstetrician/gynecologist was their feelings during a pelvic examination. They described feeling more comfortable with female obstetrician/gynecologist (100\% vs. $13 \%$, respectively, $P<0.001)$ and more embarrassed with male obstetrician/gynecologist $(36.8 \%$ vs. $0 \%$, $P<0.001$ ), and judged the pelvic examination as being more gentle $(69.2 \%$ vs. $5.4 \%, P<0.001)$. They also considered female obstetricians/gynecologists as being more sympathetic than their male counterparts $(57.9 \%$ vs. 9.3\%, $P<0.001)$.

Among the top three factors that influenced transgender men regarding their preference in choosing an obstetrician/gynecologist, only one, "ability", was chosen by the vast majority of both groups (90.5\% and 94.6\%) (Table 6; Fig. 3). The other two parameters differed according to the subject's gender preference of physician: transgender men who preferred female obstetricians/gynecologists highly ranked "sexually tolerant" (92.9\%) and "gender 
Table 3 Demographic and clinical characteristics of 98 transgender men classified by their preference for a male or female obstetrician/gynecologist (Ob/Gyn)

\begin{tabular}{|c|c|c|c|}
\hline Characteristic & Prefer female Ob/Gyn $(n=42)$ & $\begin{array}{l}\text { Prefer male Ob/Gyn or no gender preference for } \\
\text { Ob/Gyn }(n=56)\end{array}$ & $P$ Value \\
\hline Age, mean (SD) (range) & $26.7(7.42)(18-50)$ & $27.3(8.52)(18-62)$ & NS \\
\hline \multicolumn{4}{|l|}{ Origin } \\
\hline Israel & $37(88.1)$ & $45(80.4)$ & \\
\hline Other & $5(11.9)$ & $11(19.6)$ & NS \\
\hline \multicolumn{4}{|l|}{ Religious status } \\
\hline Secular & $33(80.5)$ & $9(16.1)$ & \\
\hline Religious & $8(19.5)$ & 47 (83.9) & NS \\
\hline \multicolumn{4}{|l|}{ Marital status } \\
\hline Married or with a partner & $10(25)$ & $23(41.8)$ & \\
\hline Single or divorced & $30(75)$ & $32(58.2)$ & NS \\
\hline \multicolumn{4}{|l|}{ Children } \\
\hline Yes & $5(12.5)$ & $3(5.5)$ & \\
\hline No & $35(87.5)$ & $52(94.5)$ & NS \\
\hline \multicolumn{4}{|l|}{ Education } \\
\hline Primary school & $5(11.9)$ & $1(1.8)$ & \\
\hline High school & $27(64.3)$ & $31(55.4)$ & \\
\hline College degree or higher & $10(23.8)$ & $24(42.9)$ & 0.04 \\
\hline \multicolumn{4}{|l|}{ Employment } \\
\hline Yes & $26(65)$ & $36(64.5)$ & \\
\hline No & $14(35)$ & $19(34.5)$ & NS \\
\hline \multicolumn{4}{|l|}{ Sexual orientation } \\
\hline Mainly attracted to women & $16(40)$ & $26(48.1)$ & \\
\hline Mainly attracted to men & $4(10)$ & $9(16.7)$ & \\
\hline Bisexual & $15(37.5)$ & $17(31.5)$ & \\
\hline Asexual & $5(12.5)$ & $2(3.7)$ & NS \\
\hline \multicolumn{4}{|l|}{ Psychiatric medications } \\
\hline Yes & $14(33.3)$ & $14(25)$ & NS \\
\hline No & $28(66.7)$ & $42(75)$ & \\
\hline \multicolumn{4}{|c|}{ Gender-affirming hormone therapy } \\
\hline None & $8(20.5)$ & $13(23.6)$ & \\
\hline Less than one year & $15(38.5)$ & $9(16.4)$ & \\
\hline $1-5$ years & $12(30.8)$ & $27(49.1)$ & \\
\hline More than 5 years & $4(10.3)$ & $6(10.9)$ & NS \\
\hline \multicolumn{4}{|l|}{ Upper body surgery } \\
\hline Yes & $17(40.5)$ & $29(51.8)$ & \\
\hline No & $25(59.5)$ & $27(48.2)$ & NS \\
\hline \multicolumn{4}{|l|}{ Lower body surgery } \\
\hline Yes & $0(0)$ & $4(7.1)$ & \\
\hline No & $41(100)$ & $52(92.9)$ & NS \\
\hline \multicolumn{4}{|c|}{ Preferred gender for family physician } \\
\hline Male & $2(3.3)$ & $4(7.3)$ & \\
\hline Female & $23(38.3)$ & $4(7.3)$ & \\
\hline None & $35(58.3)$ & $47(85.7)$ & $<0.001$ \\
\hline
\end{tabular}

Bold represents $P$-value under 0.05 was considered to be significant

*The values in the parentheses are percentages unless indicated otherwise 
Table 4 Preference for a male or female obstetrician/ gynecologist (Ob/Gyn) for invasive versus non-invasive Ob/Gyn procedures among transgender men

\begin{tabular}{llll}
\hline Characteristic & $\begin{array}{l}\text { Prefer female } \\
\text { Ob/Gyn } \\
(n=42)\end{array}$ & $\begin{array}{l}\text { Prefer male Ob/Gyn } \\
\text { or no Ob/Gyn gender } \\
\text { preference }(n=56)\end{array}$ & PValue \\
\hline
\end{tabular}

Invasive procedure

Gender preference for pelvic examination

$\begin{array}{lll}\text { Male } & 0(0) & 4(7.5) \\ \text { Female } & 37(97.4) & 7(13.2) \\ \text { None } & 1(2.6) & 42(79.2)\end{array}$

Gender preference for gyn consultation

$\begin{array}{lll}\text { Male } & 0(0) & 2(3.7) \\ \text { Female } & 31(77.5) & 3(5.6) \\ \text { None } & 9(22.5) & 49(90.7)\end{array}$

Gender preference for pregnancy follow-up

Male $\quad 0(0) \quad 1(1.9)$

Female $\quad 33(82.5) \quad 3(5.8)$

None $\quad 7(17.5) \quad 48(92.3)$

$<0.001$

Gender preference for fertility preservation treatments

$\begin{array}{lll}\text { Male } & 0(0) & 2(3.7) \\ \text { Female } & 24(60) & 1(1.9) \\ \text { None } & 16(40) & 51(94.4)\end{array}$

Non-invasive procedure

Gender preference for caesarean section

$\begin{array}{lll}\text { Male } & 0(0) & 0(0) \\ \text { Female } & 24(60) & 1(1.9) \\ \text { None } & 16(40) & 51(98.1)\end{array}$

Gender preference for gyn surgery

$\begin{array}{lll}\text { Male } & 1(2.5) & 1(1.9) \\ \text { Female } & 21(52.5) & 4(7.4) \\ \text { None } & 18(45) & 49(90.7)\end{array}$

Gender preference if no pelvic examination needed

$\begin{array}{lll}\text { Male } & 2(5.1) & 2(3.6) \\ \text { Female } & 22(56.4) & 2(3.6) \\ \text { None } & 15(38.5) & 51(92.7)\end{array}$

Bold represents $P$-value under 0.05 was considered to be significant

*The values in the parentheses are percentages unless indicated otherwise

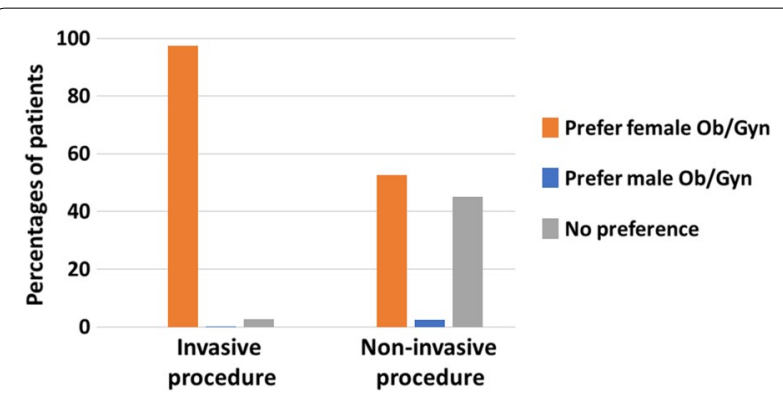

Fig. 2 Preference for a male or female Ob/Gyn for invasive (pelvic examination) versus non-invasive (no pelvic examination) procedures among transgender men tolerant" (90.5\%), while transgender men who did not prefer female obstetricians/gynecologists ranked "experience" and "knowledge" (92.9\% for both) as the other two most important characteristics. The gender of the obstetrician/gynecologist was the only parameter that was significantly different between the two groups $(33.3 \%$ vs. $3.6 \%$, respectively, $P<0.001)$.

\section{Discussion}

Many studies on SGM and health system issues have been published, but they did not identify the parameters most important to transgender men in their choice between female and male obstetricians/gynecologists. This study was designed to fill that gap. Transgender patients are a gender minority that confronts serious discrimination when approaching health services. In 2011, The National Discrimination Survey revealed that a high percentage of transgender responders experienced discrimination in various sectors of health services, such as a $24 \%$ discrimination rate at the physician's office [19]. Recent studies confirmed the negative attitude of the health system towards them that lead to their healthcare needs being unmet $[9-11,19]$. The biggest obstacle involved in transgender avoidance of healthcare systems was reported as being patient-provider interactions [20]. Healthcare providers have been implicated in low utility of healthcare services by other minorities as well [21]. Many studies examined which feature minorities prefer in their physician and identified same-gender preference as being a major one $[15,16]$. In addition to routine care, the healthcare needs of transgender people include unique treatments, such as gender-affirming hormone therapy, body-altering surgeries, psychological support, and others [22]. Family physician are the first line healthcare providers that encounter the transgender patient, manage their healthcare needs and connect them with other specialists as required [22]. There are enormous barriers when transgender people confront discriminative behavior and lack of knowledge on the part of the primary physician $[19,20]$, and those barriers interfere with the reception of appropriate quality care [23]. Similar to studies conducted among diverse minorities $[15,16,24]$, we did not find a major bias against male or female family physicians among both transgender men and women. Same-gender preference for family physician is not crucial among SGM, presumably because other parameters are more relevant to them [16, 24, 25].

The obstetrician/gynecologist has a significant role in transgender men's health. The needs of the transgender individuals are unique, such as the management of the gender-affirming hormone therapy, fertility consultation, gynecologic follow-up, etc. [19, 26, 27]. Many transgender people reportedly experience discrimination on the 
Table 5 Reasons for preference for a male or female obstetrician/gynecologist (Ob/Gyn) for specific Ob/Gyn procedures among transgender men

\begin{tabular}{|c|c|c|c|}
\hline Characteristic & Prefer female Ob/Gyn $(n=42)$ & $\begin{array}{l}\text { Prefer male Ob/Gyn or no Ob/Gyn gender preference } \\
(n=56)\end{array}$ & $P$ Value \\
\hline \multicolumn{4}{|l|}{ Pelvic examination } \\
\hline \multicolumn{4}{|c|}{ More embarrassment } \\
\hline Male & $14(36.8)$ & $0(0)$ & \\
\hline Female & $0(0)$ & $2(3.7)$ & \\
\hline No preference & $24(63.2)$ & $52(96.3)$ & $<0.001$ \\
\hline \multicolumn{4}{|l|}{ More comfortable } \\
\hline Male & $0(0)$ & $5(9.3)$ & \\
\hline Female & $38(100)$ & $7(13)$ & \\
\hline No preference & $0(0)$ & $42(77.8)$ & $<0.001$ \\
\hline \multicolumn{4}{|l|}{ More gentle } \\
\hline Male & $0(0)$ & $6(10.7)$ & \\
\hline Female & $27(69.2)$ & $3(5.4)$ & \\
\hline No preference & $12(30.8)$ & $47(83.9)$ & $<0.001$ \\
\hline \multicolumn{4}{|c|}{ Physician's characteristics } \\
\hline \multicolumn{4}{|l|}{ More sympathetic } \\
\hline Male & $0(0)$ & $5(9.3)$ & \\
\hline Female & $22(57.9)$ & $5(9.3)$ & \\
\hline No preference & $16(42.1)$ & $44(81.5)$ & $<0.001$ \\
\hline \multicolumn{4}{|l|}{ More patient } \\
\hline Male & $0(0)$ & $3(5.4)$ & \\
\hline Female & $20(50)$ & $3(5.4)$ & \\
\hline No preference & $20(50)$ & $50(89.3)$ & $<0.001$ \\
\hline \multicolumn{4}{|c|}{ Spends more time with patient } \\
\hline Male & $0(0)$ & $3(5.5)$ & \\
\hline Female & $5(12.8)$ & $0(0)$ & \\
\hline No preference & $34(87.2)$ & $52(94.5)$ & 0.01 \\
\hline \multicolumn{4}{|c|}{ Physician's professionalism } \\
\hline \multicolumn{4}{|c|}{ More understanding of transgender health } \\
\hline Male & $0(0)$ & $2(3.6)$ & \\
\hline Female & $15(38.5)$ & $3(5.4)$ & \\
\hline No preference & $24(61.5)$ & $51(91.1)$ & $<0.001$ \\
\hline \multicolumn{4}{|c|}{ More knowledgeable in transgender health } \\
\hline Male & $0(0)$ & $1(1.8)$ & \\
\hline Female & $12(30.8)$ & $2(3.6)$ & \\
\hline No preference & $27(69.2)$ & $53(94.6)$ & $<0.001$ \\
\hline \multicolumn{4}{|c|}{ Better physician in general } \\
\hline Male & $0(0)$ & $1(1.8)$ & \\
\hline Female & $11(28.2)$ & $2(3.6)$ & \\
\hline No preference & $28(71.8)$ & $53(94.6)$ & $<0.001$ \\
\hline \multicolumn{4}{|c|}{ More accepting of sexual preference } \\
\hline Male & $0(0)$ & $1(1.8)$ & \\
\hline Female & $16(40)$ & $6(10.7)$ & \\
\hline No preference & $24(60)$ & $49(87.5)$ & $<0.001$ \\
\hline \multicolumn{4}{|c|}{ More accepting of gender identity } \\
\hline Male & $1(2.5)$ & $1(1.8)$ & \\
\hline Female & $19(47.5)$ & $5(9.1)$ & \\
\hline No preference & $20(50)$ & 49 (89.1) & $<0.001$ \\
\hline
\end{tabular}

Bold represents $P$-value under 0.05 was considered to be significant

*The values in the parentheses are percentages unless indicated otherwise 
Table 6 Characteristics and percentages of the 16 factors ranked by transgender men as affecting their choice for a female or male obstetrician/gynecologist (Ob/Gyn)

\begin{tabular}{|c|c|c|c|}
\hline Characteristic & Prefer female Ob/Gyn $(n=42)$ & $\begin{array}{l}\text { Prefer male Ob/Gyn or no Ob/Gyn gender } \\
\text { preference }(n=56)\end{array}$ & $P$ Value \\
\hline \multicolumn{4}{|l|}{ Demographics } \\
\hline Age & $4(9.5)$ & $3(5.4)$ & NS \\
\hline Sex & $4(33.3)$ & $2(3.6)$ & $<0.001$ \\
\hline Religion & $5(11.9)$ & $1(1.8)$ & NS \\
\hline Marital status & 0 & 0 & \\
\hline Parental status & 0 & $1(1.8)$ & NS \\
\hline \multicolumn{4}{|l|}{ Professional skills } \\
\hline Ability (professional) & $38(90.5)$ & $53(94.6)$ & NS \\
\hline Experience & $36(85.7)$ & $52(92.9)$ & NS \\
\hline Knowledge & 34 (80.9) & $52(92.9)$ & NS \\
\hline Reputation & $15(35.7)$ & $18(32.1)$ & NS \\
\hline \multicolumn{4}{|l|}{ Qualifications } \\
\hline Board certification & $15(35.7)$ & $27(48.2)$ & NS \\
\hline Hospital affiliation & $2(4.8)$ & $4(7.1)$ & NS \\
\hline University affiliation & $1(2.4)$ & $2(3.6)$ & NS \\
\hline \multicolumn{4}{|l|}{ Other qualities } \\
\hline Personality & $31(73.8)$ & $40(71.4)$ & NS \\
\hline Availability & $19(45.2)$ & $27(48.2)$ & NS \\
\hline Sexually tolerant & $39(92.9)$ & $45(80.4)$ & NS \\
\hline Gender tolerant & $38(90.5)$ & $48(85.7)$ & NS \\
\hline
\end{tabular}

Bold represents $P$-value under 0.05 was considered to be significant

*The values in the parentheses are percentages unless indicated otherwise

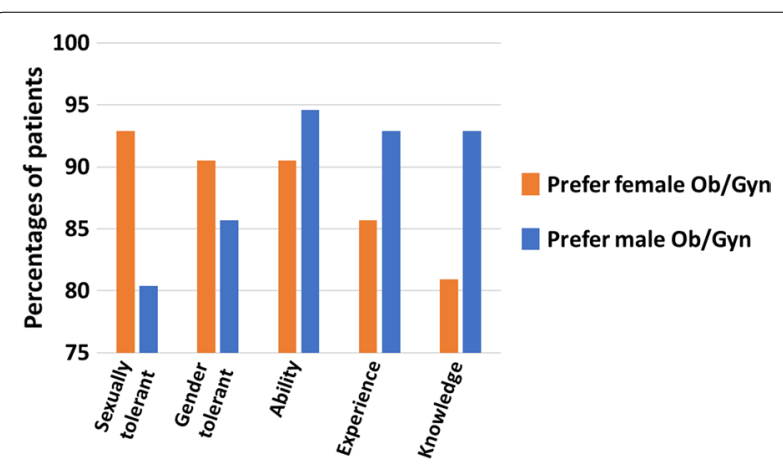

Fig. 3 Comparison between transgender men who preferred female $\mathrm{Ob} / \mathrm{Gyn}$ versus male Ob/Gyn for the top 3 factors affecting their choice

part of their obstetricians/gynecologists, and many find that experience a trigger of dysphoria [19, 26-28]. The outcome is their avoidance of treatment despite their special needs and risk factors [19, 26-28]. The discrepancy between the high needs and low usage of obstetric/ gynecologic services among minorities has previously been linked with the gender of their provider [15-17]. For example, Israeli Druze women responders described bias based on their traditional and religious beliefs [15].
Contemporary pro-active women's groups designated same-gender preference as part of their feminist dogma [13], and sexual minorities due to greater tolerance of the same-gender providers to their sexual orientation $[16$, 17].

Our working hypothesis that the invasive nature of the obstetric/gynecologic procedures would motivate transgender men to prefer a female obstetrician/gynecologist did not materialize and a small majority of the responders had no preference for obstetrician/gynecologist. Still, it should be noted that a much higher percentage of the transgender men $(42.9 \%)$ did prefer a female obstetrician/gynecologist compared with those who preferred a male (3.1\%). Moreover, excluding the responders with no preference and exploring only the responders that have preference results in $93.3 \%$ of transgender men that prefer a female obstetrician/gynecologist while only $6.7 \%$ preferred a male obstetrician/gynecologist. It should be noted that our study population is not homogeneous since it is composed of responders in different stages of their transition process. Some transgender men might be similar to cisgender men who preferred a male physician for urological care [29]. In agreement with our results, Ettner et al. did not find clear preference for same-gender surgeons by transgender people undergoing 
gender-affirming surgery despite the invasive nature of that surgery [30].

One of the main reasons for same-gender preference of other minorities was based on how they felt during pelvic examinations, e.g., more comfortable and less embarrassed $[15,16]$. As a result, their preference for a female obstetrician/gynecologist was restricted to invasive procedures $[15,16]$. The reason our responders gave for their same-gender preference during invasive procedures was similar to that other minorities, including feeling more comfortable, less embarrassed and feeling that a female obstetrician/gynecologist is gentler. However, their bias was not limited to invasive procedures but applied to non-invasive ones as well. Previous studies have demonstrated that transgender people's visit to an obstetrician/ gynecologist is associated with anxiety resulting from factors other than feeling during invasive procedures. In a survey of transgender men, 92\% reported anxiety regarding receiving gynecological care due to the following reasons: encountering gendered forms (50\%), sitting in a waiting room with cisgender women (54\%), being misgendered (59\%), having to educate the provider about transgender issues $(70 \%)$ and undergoing the gynecologic exam itself (86\%) [28]. Dutton et al. found that all of their transgender men study participants did not like receiving gynecological care not only because of the exposure of personal body part, but also because the visit itself was accompanied by an extreme emotional conflict between self-perceptions and physical anatomy [26]. The reason of our responders for their same-gender preference during non-invasive procedures presumably result from the emotional issues that emerge during the visit at the obstetrician/gynecologist.

Our transgender men responders that prefer female significantly preferred gender tolerant and sexually tolerant providers above all other factors with the exception of professional ability. Unlike our responders, religious and ethnic minorities added professional skills as interpreted by the parameters of experience and knowledge to that of ability [15], although the priorities of other SGM were influenced by their sexual orientation and gender identity $[16,17,25,31]$. Bisexual, queer or lesbian women were reported to prefer providers who were open-minded and friendly toward people of different sexual orientations [32]. SGM youth responders ranked provider qualities and interpersonal skills, such as being respectful, nonjudgmental and treating SGM equally, higher than provider knowledge and experience [24]. Frecker et al. found that the transgender men responders avoided undergoing gynecological treatment due to transgender-non-friendly and non-transgender-knowledgeable healthcare providers [28]. Having a tolerant physician apparently pales other characteristics and emphasizes the importance of such qualities to transgender men that prefer female. The association between the healthcare provider's gender and level of tolerance has already been established. SGM responders demonstrated preference for female family physicians due to their kinder, more accepting and more open character [23]. Abdessamad et al. demonstrated higher Homosexuality Attitude Scale scores among women [33]. In our study, the transgender men that prefer female considered female obstetricians/gynecologists as being far more accepting of gender identity (47.5\%) compared to male obstetricians/gynecologists (2.5\%). Their preference was significantly higher than responders who did not prefer female obstetricians/gynecologists. Same-gender preference of our responders might be ascribed to their conception that female obstetricians/ gynecologists are more tolerant than male obstetricians/ gynecologists.

To the best of our knowledge, this is the first study that addresses transgender men preferences when choosing an obstetrician/gynecologist. However, it is not without its' limitation: (1) No published data about the sociodemographic and clinical profiles of transgender persons in Israel are available, which consequently limits the possibility to examine whether our study group represents the transgender population inside and outside Israel. However, based on previous studies we can conclude that some of the characteristics including religious status [34], education [35], employment [36, 37], sexual orientation [34], mental disorders [35, 36], and gender-affirming surgeries $[38,39]$, are representative. Furthermore, most of the transgender adolescents and adults nationwide are referred to our hospital because it is part of a national center for transgender health medicine. This enables the adequate representation of all strata of the transgender population. In addition, the study was conducted in two clinics, in and out of the hospital, to increase the population's representation. Still, we are aware of this weakness thus calling for further studies on larger populations. (2) The study was conducted in only two centers, therefore, interpersonal relationships with physicians might influence patient preference. However, both clinics are large and enable exposure to a variety of physicians. (3) Both centers are located in the center of Tel Aviv, the most liberal area in Israel. Nonetheless, as our study is relatively large, and was performed, as already mentioned, in a multi-disciplinary clinic that serves as the national referral center for gender dysphoric patients from across Israel it very likely reflects the preferences of this unique population. (4) Most of the patients were exposed to female physicians in the study clinics (75\% female physicians). It is possible that if the exposure rate to male physicians was higher, the results would have changed. (5) Respondents were not asked if they prefer transgender 
clinician. This knowledge is significant and might influence the results. Further studies that include this information are desirable.

We found that small majority of the transgender men do not exhibit preference for obstetricians/gynecologists' gender, though their tendency was to prefer female obstetrician/gynecologist. Transgender men tendency was associated with the preference for tolerant obstetrician/gynecologist and the assumption that female obstetricians/gynecologists are more accepting and tolerant for gender and sexual minority patients.

Their unique health requirements and the discriminatory environment they encounter in healthcare facilities drive transgender men to seek an open-minded and tolerant obstetrician/gynecologist that accepts their gender identity. Educating the medical staff about their special needs and establishing dedicated SGM centers staffed with high percentages of female healthcare providers are highly recommended.

\section{Policy implications}

Despite the increased understanding of the value of treating transgender patients in a knowledgeable, mindful and supportive manner, transgender health policies and their healthcare delivery issues are still lacking. There is negligible public and governmental awareness of the crucial needs of the transgender population in general, and specifically of their unique healthcare needs that are different from traditional ones [9-11, 19, 26-28]. Transgender issues are either not included or have not been updated in medical studies $[19,40]$. There is a dearth of education on the issues that concern transgender people's health, and even more so with regard to issues of gynecology and reproduction [41, 42]. Medical providers, such as obstetricians/gynecologists, acquire their knowledge from several limited resources (World Professional Association for Transgender Health-Standards of Care and Diagnostic and Statistical Manual of Mental Disorders), and are usually not aware of the unique physical and mental needs of their transgender patients [28, 40, 43, 44]. Hospitals and healthcare centers lack policies and fundamental knowledge about the transgender population's healthcare issues [9-11, 19, 26-28], often preferring to avoid them altogether.

The transgender healthcare field of care is still in its infancy, but there are considerable efforts to promote the rights of transgender people to receive equal and competent healthcare services. Formal recommendations for specific education objectives regarding transgender healthcare were published by the Council of Resident Education in Obstetrics and Gynecology in the USA [45]. The American College of Obstetricians and Gynecologists has produced recommendations on care, support, education and awareness for obstetrician and gynecologist specialists regarding their transgender patients [46]. Additionally, there are universities in the USA and Canada that include updated and expanded curriculum on the care of transgender populations in their undergraduate and graduate medicine programs [45, 47-50]. In the UK, University College London and Bristol Medical School have implemented sessions to raise awareness of SGM health inequalities [51]. In Israel, the Tel Aviv University includes transgender care in its obstetricians/gynecologists continuing medical education training [52]. There are updated sources of information about transgender care, including medical books, e.g., dedicated chapters are included in the new edition of Speroff's Clinical Gynecologic Endocrinology and Infertility [53]. New web-based resources include SGM educational materials and workshops online that provide updated knowledge and education about the transgender population's healthcare $[44,54,55]$. Several new dedicated SGM interdisciplinary healthcare centers that are composed of transgender-friendly interdisciplinary healthcare providers have also been established [56, 57]. The Tel Aviv Medical Center (Tel Aviv, Israel) recently founded a national center for transgender health medicine which includes transgender-friendly endocrinologists, plastic surgeons, skin specialists, psychologists and obstetrician/gynecologist specialists [58].

We contend that certain policy changes are warranted in order to encourage greater accessibility by transgender people to the healthcare system. We urge increasing public awareness and establishing governmental policies to encourage additional changes in approaches to healthcare issues, such as campaigning to educate providers, establishing enlightened hospital policies, creating dedicated centers, etc. We suggest creating more dedicated SGM-friendly clinics and centers that will staff tolerant and trans-experienced experts, including obstetricians/ gynecologists with high percentages of female healthcare providers. We strongly recommend establishing formal protocols and guidelines regarding transgender people's healthcare that will be an integral part of the undergraduate and graduate medical students' curriculum, in addition to periodical mandatory training programs and workshops for physicians and experts in transgender medicine. The overall aim is to achieve basic knowledge among the entire population of healthcare providers that will enable them to provide basic mindful and tolerant treatment to transgender patients. Such interventions have already proven to be successful and shown to have improved providers' attitudes and professional skills in the USA and UK $[55,59]$. We urge the promotion and financial support of these efforts through fellowships and the inclusion of sub-specialties in SGM health programs 
that will allow young physicians to become experts in SGM medicine. For example, obstetrician/gynecologist experts in fertility will be able to gain advanced knowledge and expertise in SGM medicine and apply these skills to provide suitable treatments to transgender individuals (e.g., fertility preservation or pregnancy follow-ups for transgender men) [60]. We believe that the combination of mandatory basic training to all general healthcare providers together with elective fellowship/ sub-specialization training to healthcare experts will enable transgender patients to receive compassionate, competent, and appropriate healthcare.

\section{Conclusions}

Transgender men comprise a marginalized minority that their usage of healthcare services is low despite their high levels of medical needs. A major factor in their avoidance to seek such services is patient-provider interactions. Most transgender men that reported gender preference when choosing an obstetrician/gynecologist preferred female physicians. Their choice was associated with the assumption that female obstetricians/gynecologists are more tolerant towards their transgender male patients. In order to overcome such avoidance and encourage greater accessibility to the healthcare system, there is a need to increase the awareness of the population, specifically, that of healthcare providers, to the unique physical and mental healthcare needs of transgender patients. Educating and training the medical staff about those unique needs are mandatory in order to overcome the paucity of education on these issues, and to turn around the discriminatory environment confronted by the transgender population. Establishing dedicated SGM interdisciplinary healthcare centers staffed with tolerant and trans-experienced experts, including obstetricians/gynecologists with high percentages of female healthcare providers, is highly recommended.

\section{Abbreviations \\ LGBTQ: Lesbian, gay, bisexual, transgender and queer; OB\GYN: Obstetrician/ gynecologist; SD: Standard deviation; SGM: Sexual and gender minorities.}

\section{Acknowledgements}

We are grateful to the people who participated in this study and agreed to share their preferences with us.

\section{Authors' contributions \\ D.P.L., and H.A. were involved in the project development, study design, data management, data analysis, and manuscript writing. I.Y., G.W.K., Y.G., Y.S., and S.A. data collection and manuscript editing. A.G., and F.A. data analysis and manuscript editing. All contributors reviewed the manuscript and gave their approval of the final version. All authors read and approved the final manuscript.}

\section{Funding}

No external funding was either sought or obtained for this study.
Availability of data and materials

Data are available upon request.

\section{Declarations}

\section{Ethics approval and consent to participate}

This study was approved by the institutional review board (Helsinki) of the Tel Aviv Medical Center (\#0455-17-TLV).

\section{Consent to participate}

Anonymous questionnaire-no consent form is required. Approved by the institutional review board (Helsinki) of the Tel Aviv Medical Center.

\section{Consent for publication}

Not applicable.

\section{Competing interests}

The authors declare that they have no conflict of interest.

\section{Author details}

${ }^{1}$ Department of Obstetrics and Gynecology, Sheba Medical Center, Tel Hashomer, Affiliated to the Sackler Faculty of Medicine, Tel Aviv University, Tel Aviv, Israel. ${ }^{2}$ Institute of Endocrinology, Metabolism and Hypertension, Tel Aviv Sourasky Medical Center, Affiliated to the Sackler Faculty of Medicine, Tel Aviv University, Tel Aviv, Israel. ${ }^{3}$ Department of Family Medicine, Clalit Gan-Meir LGBT Clinic, Tel Aviv District, Israel. ${ }^{4}$ Sara Racine IVF Unit, Department of Obstetrics and Gynecology, Lis Maternity Hospital, Tel Aviv Sourasky Medical Center, Affiliated to the Sackler Faculty of Medicine, Tel Aviv University, Tel Aviv, Israel. ${ }^{5}$ Department of Obstetrics and Gynecology, Chaim Sheba Medical Center (Tel Hashomer), Ramat Gan, Israel.

Received: 5 May 2021 Accepted: 4 February 2022

Published online: 11 February 2022

\section{References}

1. Coleman E, Bockting W, Botzer M, Cohen-Kettenis P, DeCuypere G, Feldman J, et al. Standards of care for the health of transsexual, transgender, and gender-nonconforming people, Version 7. Int J Transgenderism. 2012;13(4):165-232.

2. Baker KE. Findings from the behavioral risk factor surveillance system on health-related quality of life among US transgender adults, 2014-2017. JAMA Intern Med. 2019;179(8):1141-4.

3. Johns M, Lowry R, Andrzejewski J, Barrios L, Demissie Z, Mcmanus T, et al. Transgender identity and experiences of violence victimization, substance use, suicide risk, and sexual risk behaviors among high school students_-19 states and large urban school districts, 2017. MMWR Morb Mortal Wkly Rep. 2019;6:66

4. Winter S, Diamond M, Green J, Karasic D, Reed T, Whittle S, et al. Transgender people: health at the margins of society. The Lancet. 2016;388(10042):390-400.

5. Coulter RWS, Blosnich JR, Bukowski LA, Herrick AL, Siconolfi DE, Stall RD. Differences in alcohol use and alcohol-related problems between transgender- and nontransgender-identified young adults. Drug Alcohol Depend. 2015;154:251-9.

6. Lombardi E. Transgender health: a review and guidance for future research - proceedings from the Summer Institute at the Center for Research on Health and Sexual Orientation, University of Pittsburgh. Int J Transgenderism. 2010;12(4):211-29.

7. White Hughto JM, Reisner SL, Pachankis JE. Transgender stigma and health: a critical review of stigma determinants, mechanisms, and interventions. Soc Sci Med. 2015;1982(147):222-31.

8. World Health Organization. Transgender People and HIV. 2015; 1-34.

9. The Lancet Diabetes \& Endocrinology. Transgender health: access to care under threat. Lancet Diabetes Endocrinol. 2018;6(6):427.

10. Sbragia JD, Vottero B. Experiences of transgender men in seeking gynecological and reproductive health care: a qualitative systematic review protocol. JBI Database Syst Rev Implement Rep. 2019;17(8):1582-8. 
11. Committee Opinion no. 512: health care for transgender individuals. Obstet Gynecol. 2011 Dec;118(6):1454-8.

12. Nahata L, Tishelman AC, Caltabellotta NM, Quinn GP. Low fertility preservation utilization among transgender youth. J Adolesc Health Off Publ Soc Adolesc Med. 2017;61(1):40-4.

13. Baskett TF. What women want: don't call us clients, and we prefer female doctors. J Obstet Gynaecol Can JOGC J Obstet Gynecol Can JOGC. 2002;24(7):572-4.

14. Piper I, Shvarts S, Lurie S. Women's preferences for their gynecologist or obstetrician. Patient Educ Couns. 2008;72(1):109-14.

15. Amer-Alshiek J, Alshiek T, Amir Levy Y, Azem F, Amit A, Amir H. Israeli Druze women's sex preferences when choosing obstetricians and gynecologists. Isr J Health Policy Res. 2015;4(1):13.

16. Amir H, Gophen R, Amir Levy Y, Hasson J, Gordon D, Amit A, et al. Obstetricians and gynecologists: Which characteristics do Israeli lesbians prefer? J Obstet Gynaecol Res. 2015:41(2):283-93.

17. Geddes VA. Lesbian expectations and experiences with family doctors. How much does the physician's sex matter to lesbians? Can Fam Physician Med Fam Can. 1994;40:908-20.

18. Owen-Smith AA, Woodyatt C, Sineath RC, Hunkeler EM, Barnwell LT, Graham A, et al. Perceptions of barriers to and facilitators of participation in health research among transgender people. Transgender Health. 2016;1(1):187-96

19. Houssayni S, Nilsen K. Transgender competent provider: identifying transgender health needs, health disparities, and health coverage. Kans J Med. 2018;11(1):1-18.

20. Jaffee KD, Shires DA, Stroumsa D. Discrimination and delayed health care among transgender women and men: implications for improving medical education and health care delivery. Med Care. 2016;54(11):1010-6.

21. Bulatao RA, Anderson NB, editors. Understanding racial and ethnic differences in health in late life. Understanding racial and ethnic differences in health in late life. Washington, DC; 2004.

22. Radix AE. Addressing needs of transgender patients: the role of family physicians. J Am Board Fam Med. 2020;33(2):314LP-321LP.

23. Bosse JD. Sexual and gender identity development in young adults and implications for healthcare. Curr Sex Health Rep. 2019;1 1(4):274-86.

24. Hoffman ND, Freeman K, Swann S. Healthcare preferences of lesbian, gay, bisexual, transgender and questioning youth. J Adolesc Health Off Publ Soc Adolesc Med. 2009;45(3):222-9.

25. Ginsburg KR, Winn RJ, Rudy BJ, Crawford J, Zhao H, Schwarz DF. How to reach sexual minority youth in the health care setting: the teens offer guidance. J Adolesc Health Off Publ Soc Adolesc Med. 2002;31(5):407-16.

26. Dutton L, Koenig K, Fennie K. Gynecologic care of the female-to-male transgender man. J Midwifery Womens Health. 2008;53(4):331-7.

27. Mayhew AC, Cohen A, Gomez-Lobo V. Transgender men and the gynecologist. Clin Obstet Gynecol. 2020;63(3):588-98.

28. Frecker $\mathrm{H}$, Scheim $\mathrm{A}$, Leonardi $\mathrm{M}$, Yudin M. Experiences of transgender men in accessing care in gynecology clinics [24G]. Obstet Gynecol. 2018:131:66.

29. Amir H, Beri A, Yechiely R, Amir Levy Y, Shimonov M, Groutz A. Do urology male patients prefer same-gender urologist? Am J Mens Health 2016;12(5):1379-83

30. Ettner R, Ettner F, White T. Choosing a surgeon: an exploratory study of factors influencing selection of a gender affirmation surgeon. Transgender Health. 2016;1 (1):124-8.

31. Gridley SJ, Crouch JM, Evans Y, Eng W, Antoon E, Lyapustina M, et al. Youth and caregiver perspectives on barriers to gender-affirming health care for transgender youth. J Adolesc Health Off Publ Soc Adolesc Med. 2016;59(3):254-61.

32. Mulligan E, Heath M. Seeking open minded doctors-how women who identify as bisexual, queer or lesbian seek quality health care. Aust Fam Physician. 2007;36(6):469-71.

33. Abdessamad HM, Yudin MH, Tarasoff LA, Radford KD, Ross LE. Attitudes and knowledge among obstetrician-gynecologists regarding lesbian patients and their health. J Womens Health. 2013;22(1):85-93.

34. Aparicio-García ME, Díaz-Ramiro EM, Rubio-Valdehita S, López-Núñez MI, García-Nieto I. Health and Well-Being of Cisgender, Transgender and NonBinary Young People. Int J Environ Res Public Health. 2018;15:66.

35. Rimes KA, Goodship N, Ussher G, Baker D, West E. Non-binary and binary transgender youth: comparison of mental health, self-harm, suicidality, substance use and victimization experiences. Int J Transgenderism. 2017;20(2-3):230-40

36. Beckwith N, McDowell MJ, Reisner SL, Zaslow S, Weiss RD, Mayer KH, et al. Psychiatric epidemiology of transgender and nonbinary adult patients at an Urban Health Center. LGBT Health. 2019;6(2):51-61.

37. Motmans J, Ponnet K, Cuypere G. Sociodemographic characteristics of trans persons in Belgium: a secondary data analysis of medical, state, and social data. Arch Sex Behav. 2015;1(44):1289-99.

38. Nolan IT, Kuhner CJ, Dy GW. Demographic and temporal trends in transgender identities and gender confirming surgery. Transl Androl Urol. 2019:8(3):184-90.

39. Crissman H, Randolph JFJ. Role for OBGYNs in gender-affirming surgical care of transgender and gender nonconforming individuals. Clin Obstet Gynecol. 2018;61(4):722-30.

40. MacKinnon KR, Ng SL, Grace D, Sicchia SR, Ross LE. Protocols as curriculum? Learning health advocacy skills by working with transgender patients in the context of gender-affirming medicine. Adv Health Sci Educ Theory Pract. 2020;25(1):7-18.

41. Dubin SN, Nolan IT, Streed CG, Greene RE, Radix AE, Morrison SD. Transgender health care: improving medical students' and residents' training and awareness. Adv Med Educ Pract. 2018;9:377-91.

42. Streed CG, Lunn MR, Siegel J, Obedin-Maliver J. Meeting the patient care, education, and research missions: academic medical centers must comprehensively address sexual and gender minority health. Acad Med J Assoc Am Med Coll. 2021;96(6):822-7.

43. Hoffkling A, Obedin-Maliver J, Sevelius J. From erasure to opportunity: a qualitative study of the experiences of transgender men around pregnancy and recommendations for providers. BMC Pregnan Childb. 2017:17(2):332

44. Rolls J, Davis J, Backman R, Wood T, Honda T. Curricular approaches to transgender health in physician assistant education. Acad Med. 2020;95(10):66

45. Vinekar K, Rush SK, Chiang S, Schiff MA. Educating obstetrics and gynecology residents on transgender patients: a survey of program directors. Obstet Gynecol. 2019;133(4):691-9.

46. Health Care for Transgender and Gender Diverse Individuals: ACOG Committee Opinion Summary, Number 823. Obstet Gynecol. 2021;137(3):554-5.

47. Nolan IT, Blasdel G, Dubin SN, Goetz LG, Greene RE, Morrison SD. Current state of transgender medical education in the United States and Canada: update to a scoping review. J Med Educ Curric Dev. 2020:7:2382120520934813.

48. O'Leary KB, Kunkel GH. Restructuring LGBTQ Curriculum in Medical Schools. Acad Psychiatry. 2021;6:66.

49. Najor AJ, Kling JM, Imhof RL, Sussman JD, Nippoldt TB, Davidge-Pitts CJ. Transgender health care curriculum development: a dual-site medical school campus pilot. Health Equity. 2020;4(1):102-13.

50. U of T expands LGBTQ+ health curriculum for medical residents / The Charlatan, Carleton's independent newspaper [Internet]. [cited 2021 Jul 26]. https://charlatan.ca/2020/10/u-of-t-expands-lgbtq-health-curri culum-for-medical-residents/.

51. Tollemache N, Shrewsbury D, Llewellyn C. Que(e) rying undergraduate medical curricula: a cross-sectional online survey of lesbian, gay, bisexual, transgender, and queer content inclusion in UK undergraduate medical education. BMC Med Educ. 2021;21(1):100.

52. Obstetrics an Gynecology - 2021 — Hybrid Course - The Academic center for CME in Medicine - Tel Aviv University [Internet]. [cited $2021 \mathrm{Jul}$ 26]. https://med.tau.ac.il/cme-6.

53. Taylor HS, Pal L, Emre S. Speroff's clinical gynecologic. Endocrinol Infertil. 2011:66:1879-920.

54. Transgender Healthcare Curriculum | Obstetrics and Gynecology | Michigan Medicine | University of Michigan [Internet]. [cited 2021 Jul 26]. https://medicine.umich.edu/dept/obgyn/education/continuing-medic al-education-cme/transgender-healthcare-curriculum.

55. Sekoni AO, Gale NK, Manga-Atangana B, Bhadhuri A, Jolly K. The effects of educational curricula and training on LGBT-specific health issues for healthcare students and professionals: a mixed-method systematic review. J Int AIDS Soc. 2017:20(1):21624.

56. Chen D, Hidalgo MA, Leibowitz S, Leininger J, Simons L, Finlayson C, et al. Multidisciplinary care for gender-diverse youth: a narrative review 
and unique model of gender-affirming care. Transgender Health. 2016;1 (1):117-23.

57. Eyssel J, Koehler A, Dekker A, Sehner S, Nieder TO. Needs and concerns of transgender individuals regarding interdisciplinary transgender healthcare: a non-clinical online survey. PLoS ONE. 2017;12(8):e0183014-e0183014.

58. The center for gender healthcare. Ichilov. [Internet]. [cited 2021 Jul 26]. https://www.tasmc.org.il/Internalmed/Endocrinology/Pages/GenderIdentity-Disorder.aspx.

59. Thomas DD, Safer JD. A simple intervention raised resident-physician willingness to assist transgender patients seeking hormone therapy. Endocr Pract Off J Am Coll Endocrinol Am Assoc Clin Endocrinol. 2015;21(10):1134-42.

60. Mount Sinai Creates LGBTQ+ Medical Fellowship That Will Serve as a National Model of Care | Mount Sinai Today [Internet]. [cited 2021 Jul 26]. https://health.mountsinai.org/blog/mount-sinai-creates-lgbtq-medicalfellowship-that-will-serve-as-a-national-model-of-care/.

\section{Publisher's Note}

Springer Nature remains neutral with regard to jurisdictional claims in published maps and institutional affiliations.

- fast, convenient online submission

- thorough peer review by experienced researchers in your field

- rapid publication on acceptance

- support for research data, including large and complex data types

- gold Open Access which fosters wider collaboration and increased citations

- maximum visibility for your research: over $100 \mathrm{M}$ website views per year

At BMC, research is always in progress.

Learn more biomedcentral.com/submissions 